\title{
Employee Commitment: The Relationship between Employee Commitment and Job Satisfaction
}

\author{
Hassan Mahmood Aziz ${ }^{1}$, Baban Jabbar Othman², Bayar Gardi ${ }^{3}$, Shahla Ali Ahmed ${ }^{4}$, \\ Bawan Yassin Sabir ${ }^{5}$, Nechirwan Burhan Ismael ${ }^{6}$, Pshdar Abdalla Hamza ${ }^{7}$, Sarhang \\ Sorguli ${ }^{8}$, Bayad Jamal Ali ${ }^{9}$, Govand Anwar ${ }^{10}$
}

\begin{abstract}
${ }^{1}$ Department of Accounting and Finance, Faculty of Economics and Administrative Sciences, Cyprus International University, Mersin 10, Haspolat 99040, Cyprus.

${ }^{2,3,5,8}$ Department of Accounting, College of Administration and Financial Sciences, Knowledge University, Kirkuk Road, 44001 Erbil, Kurdistan Region, Iraq.

${ }^{4}$ Department of Guidance and Psychological Counseling, Atatürk Faculty of Education, Near East University, Turkey

${ }^{6}$ Department of Accounting, Cihan University - Duhok, Kurdistan Region, Iraq.

${ }^{7}$ Department of Business Administration, Kurdistan Technical Institute, Sulaymaniyah, Iraq.

${ }^{9}$ Business Administration Department, Komar University of Science and Technology, Sulaimani 46001, Kurdistan Region - Iraq

${ }^{10}$ Department of Business Administration, College of Administration and Financial Sciences, Knowledge University,44001 Erbil,

Kurdistan Region, Iraq
\end{abstract}

Received: 11 Feb 2021; Received in revised form: 26 Apr 2021; Accepted: 18 May 2021

(C)2021 The Author(s). Published by TheShillonga. This is an open access article under the CC BY license

(https://creativecommons.org/licenses/by/4.0/)

\begin{abstract}
The aim of the current study is to examine the association between employee commitment and job satisfaction at selected private universities in Kurdistan region of Iraq. Organizational commitment predicts work variables, for example, turnover, hierarchical citizenship conduct, and employment execution. A percentage of the elements, for example, part stretch, strengthening, work shakiness and employability, and appropriation of authority have been appeared to be associated with a laborer's feeling of organizational commitment. This research was carried out at the three different private universities. A quantitative method was used to gather relevant information regarding the relationship between organizational commitment and job satisfaction. The results revealed that all three independent factors are correlated with job satisfaction. The result can be used as a guiding method for the university's management to increase their employees' commitment. Job satisfaction has a positive relation with employee commitment if employees are satisfied, they are organizationally committed we found that job satisfaction has a positive impact on employee commitment.
\end{abstract}

Keywords—Job Satisfaction, Employee Commitment, Higher Education.

\section{INTRODUCTION}

Organizational commitment is $\mathrm{t}$ is the individual's mental connection to the organization. The premise behind huge numbers of these studies was to discover approaches to enhance how specialists feel about their works so that these laborers would turn out to be more dedicated to their organization. Organizational commitment predicts work variables, for example, turnover, hierarchical citizenship conduct, and employment execution. A percentage of the elements, for example, part stretch, strengthening, work shakiness and employability, and appropriation of authority have been appeared to be associated with a laborer's feeling of organizational commitment (Abdullah \& Othman, 2019). Affective commitment: Affective commitment: Is understood as the employee's constructive emotional bonding to the organization. Such an employee strongly associates himself/ herself with organizational goals and seeks to stay with the organization because he/she wishes to do so (Anwar \& Abdullah, 2021).

Continuance commitment: Here the emotional quotient is largely moot and the employee perceives it to be very costly to lose organizational membership (Gardi et al. 2020). This 
could be for a host of reasons right from financial costs of salary and benefits to social costs of ties and reputation. Such an employee stays with the organization because he or she is tied in (Prabhu et al. 2020).

Normative commitment: There is an obligatory notion at play here. The employee feels to return the value commitments made in him/ her by the organization (Anwar \& Shukur, 2015). The loyalty aspect is strong- either due to individualized value perceptions that direct behavior or due to social norms that apply to the context and relate with the environment the organization belongs to (Sultan et al. 2020).

Job satisfaction is an issue for all organizations regardless of whether in broad daylight or private organizations or working advanced or immature countries the idea of job satisfaction has been created from numerous points of view by a wide range of scientists and experts (Abdullah \& Othman,2015). A standout amongst the most broadly utilized definitions as a part of authoritative exploration is that of (Gardi, 2021) who characterizes job satisfaction as "a pleasurable or positive emotional state resulting from the appraisal of one's job or job experiences (Top \& Ali, 2021). Others have characterized it as just how content an individual is with his or her job; whether he or she prefers the employment or not. It is evaluated at both the worldwide level (regardless of whether the individual is fulfilled by the job overall), or at the feature level (regardless of whether the individual is fulfilled by various parts of the job). (Anwar \& Abd Zebari, 2015) records 14 basic aspects: (Ismael et al. 2021) Gratefulness, Correspondence, Colleagues, Incidental advantages, job conditions, Nature of the work, organizations, Self-improvement, Strategies and systems (Demir et al. 2020), Advancement opportunities, Acknowledgment, Security, and Supervision. A later definition of the concept of job satisfaction is from (Anwar \& Surarchith, 2015), who have noticed that job satisfaction incorporates multidimensional mental reactions to an individual's job, and that these individual reactions have psychological (evaluative), full of feeling (or passionate), and behavioral components. Job satisfaction scales change in the degree to which they survey the emotional sentiments about the job or the subjective appraisal of the job (Ali, 2021). Affective job satisfaction is a subjective develop speaking to an enthusiastic feeling people have about their job(Othman et al. 2019). Thus, emotional employment fulfillment for people mirrors the level of joy or bliss their employment all in all instigates. Intellectual occupation fulfillment is a more target and intelligent assessment of different features of a vocation (Ali, 2020). Intellectual occupation fulfillment can be onedimensional on the off chance that it includes assessment of only one aspect of an occupation, for example, pay or maternity leave, or multidimensional if two or more features of a vocation are all the while assessed. Subjective occupation (Khan \& Abdullah, 2019) fulfillment does not evaluate the level of delight or joy that emerges from particular employment features, yet rather gages the degree to which those occupation aspects are judged by the occupation holder to be attractive in examination with targets they themselves set or with different occupations(Othman et al. 2019). While psychological employment fulfillment may achieve emotional occupation fulfillment, the two builds are unmistakable, not as a matter of course specifically related, and have distinctive predecessors and consequences (Anwar, 2017).

\section{Research problem}

In this research which is between organizational commitment and job satisfaction we will try to show the relations and the impact of employees' commitment to job satisfaction and how much is an employee satisfied while he/she is committed to the job and the show that every committed employee is stifled or not, and we will try to study the degree various factors contribute to their level of commitment, is really important to boosting up their satisfaction?

\section{Research questions}

Below are the main research questions:

1. How does job satisfaction impact employee commitment?

2. Is there a positive significant relation between employee commitment and job satisfaction?

3. To what degree various factors contribute to their level of commitment, is really important to boosting up their satisfaction?

\section{Research Objectives}

Below are the main research objectives:

1. Identifying the impact of job satisfaction on their employee commitment

2. demonstrate positive significant relation between employee commitment and job satisfaction

3. Categorize factors that contribute employee level of commitment which rise job satisfaction

\section{LITTERATEUR REVIEW}

\section{Organizational Commitment}

The business organizations know about the significance of employee commitment and its part in motivating employees. The motivation behind this study was to recognize the effect of Employees' Commitment on supported efficiency in universities in Kurdistan Employee commitment is the psychological attachment and the 
resulting loyalty of an employee to an organization (Anwar, 2016). In today's competitive world each organization is confronting new difficulties in regards to maintained efficiency and creating committed workforce (Andavar et al. 2020). Presently a day's no organization can perform at top levels unless every employee is focused on the organization's goals. Consequently, it is critical to understand the idea of commitment and its practical result. A vast quantity of studies has been directed to explore the idea of organizational commitment (OC). Still, commitment is the most difficult and researchable idea in the fields of management, organizational behavior(Abdulla et al. 2017). There have been a few measures and definitions about OC. We have three types of organizational commitment (Normative, affective and continuous commitments) each one of these show a level of commitment of an employee to the organization which determines how much each employee committed to the organization. Some people are committed to their jobs because they love what they do, (Anwar \& Balcioglu, 2016) or because their goals align with those of the company. Others might stay because they fear what they could lose if they leave(Abdullah \& Abdul Rahman, 2015). Still others might stay because they feel obligated to the company, or to their manager (Faraj et al. 2021). Clearly, some of these types of commitment can have a negative effect on a person's well-being, self-respect, and job satisfaction. So, how can you avoid this, but still help team members feel committed to your team, or organization, in a positive way? In this article we'll explore three common types of commitment, and we'll look at how you can make changes to improve team member engagement and loyalty in an effective and positive way(Hameed \& Anwar, 2018).

Organization commitment alludes to the employee's passionate connection to, recognizable proof with, and contribution in the association, as per (Damit et al. 2019), Organizational commitment is described as employees' ability to add to organizational objectives. At the point when employees are certain that they will develop and learn with their present bosses, their level of duty to stay with that specific organizations higher Commitment appears when a man, by making a side wager, joins unessential premiums with a predictable line of action. (Anwar \& Climis, 2017), relates commitment with (Anwar \& Ghafoor, 2017), the nature of the relationship of the part to the framework overall. (Prabhu et al. 2020) characterizes commitment as "The eagerness of social performing artists to give their vitality and reliability to social frameworks (Ali, 2016), the connection of identity frameworks to social relations, which are seen as self-expressive (Anwar \& Qadir, 2017) characterized organizational commitment as the conduct that associates representatives to the organization.
Organizational commitment is the means by which a devoted the worker feels to the organization (Abdullah \& Rahman, 2015). Meyer and Allen (1991), Dunham et al. (1994) recognized organizational commitment as three kinds which are affective, continuous and normative. Affective commitment is the employees' feelings toward joining the organization, continuous commitment is employees' perceptions of costs if leaving the organization and normative commitment is employees' perceptions of their duties and promises toward the organization(Abdullah, 2019). According to (Anwar \& Louis, 2017), employee commitment is in respect to the laborers' connection to or support in the organizations in which they employed. Employee commitment is noteworthy since it figures out if workers are liable to leave their employments or imdemonstrate execution. Various studies have identified with employee commitment (Ali, 2014). According to (Prabhu et al. 2020), organizational commitment construct includes elements of desires, needs, and obligations are represented in the three components of organizational commitment. Three important components related to the definition of organizational commitment has been found in the literature is affective commitment, continuance commitment and normative commitment (Ganeshkumar et al. 2019). According to (Abdullah \& Afshar, 2019), several alternative models of commitment were proposed in the 1980s and early 1990s; multidimensionality was common to all (Abdullah \& Rahman, 2015). There are threecomponent model of affective, continuance, and normative commitment as mentioned above (Ali et al. 2021). According to Meyer and Allen (1997) All the three segments in particular Affective Commitment that is mental connection to organization; Continuance Commitmentcosts connected with leaving the organization; and Normative Commitment-saw commitment to stay with the association have suggestions for the proceeding with investment of the person in the organization (Abdullah, 2018). The higher a employee's level of instruction is, the lower that individual's level of organizational commitment (Saleh et al. 2021). Affective commitment alludes to the feeling of distinguishing proof as an individual from the organization and inclusion in the organization (Othman \& Abdullah, 2016). Affective commitment responsibility is commitment of duty there is a positive association between the individual and the association on the grounds that both have comparative qualities (Abdullah \& Othman, 2016). The individuals who stay in their organizations with a solid commitment hold their position since they require the occupation, as well as in light of the fact that they need it (Abdullah \& Othman, 2021). Affective commitment is the procedure in which individuals carry on and consider their 
relationship with the organization (Abdullah \& Abdul Rahman, 2015).

Continuation commitment alludes to an individual's awareness of the expense to leave the organization (Anwar \& Abdullah, 2021). The counterpart to affective organizational commitment is continuance organizational commitment, which considers the idea that individuals do not leave a company for fear of losing their benefits, taking a pay cut, and not being able to find another job (Anwar \& Shukur, 2015). Continuation commitment is an auxiliary marvel which happens as a consequence of the exchanges of people and organizations (Yang, 2008). At that point, continuance commitment is identified with one's experience and what one has given to an organization. There is accordingly trouble in "surrendering it" and the obscure "open door expense" of leaving the organization or having few or no options. In addition, Meyer et al. (1993) expressed that aptitudes and instruction are not effortlessly exchanged to other organization which tends to expand laborers' dedication to their present organization. Continuation responsibility connected with the experience that has been given to the organization (Anwar \& Abd Zebari, 2015). Representatives with a high managed duty think that it's hard to leave the association as a result of apprehension of the open-door cost borne when leaving the organization or on the grounds that they have next to zero option opportunities outside the organization (Anwar \& Surarchith, 2015). The individuals who stay inside of their organization with a solid continuance commitment are there in light of the fact that they require it. Continuance commitment reflects financial binds to the organization taking into account the expenses connected with leaving the organization. Research into continuance commitment proposes that this part comprises of two related submeasurements: giving up of one's own priorities and saw absence of options (Anwar, 2017). In other words, employee will remain in the organization because there are no other job alternatives outside the organization or because it is not accepted elsewhere (Anwar, 2016).

Normative commitment refers to loyalty and a sense of debt to the organization based on moral obligation and usually develops as a result of socialization practices and based on a sense of duty and loyalty (Abdulla et al. 2017). Normative commitment explains the employees with strong normative commitment will remain with an organization by virtue of their belief that it is the "right and moral" thing to do (Anwar \& Balcioglu, 2016). Normative commitment is defined as a strong social emphasis on the obligations and the tendency of individuals (Hameed \& Anwar, 2018). Anwar \& Ghafoor, (2017) argued that normative commitment to the organization develops based on a collection of pressures that individuals feel during their early socialization from family and culture and during their socialization as newcomers to the organization. Besides that, normative commitment might also develop because of the "psychological contract" between an employee and the organization (Anwar \& Climis, 2017). Normative commitment refers to feelings and obligations of employees to remain employed in the organization. Furthermore, normative commitment can increase when an individual feels loyal to his employer or responsible to work for the benefits that he gets from the organization as a result of the desire to compensate the favors received from the institution (Anwar \& Qadir, 2017).

Job satisfaction is characterizing as the emotions or a general state of mind of the representatives in connection with their employments and the job components, for example, the workplace, working conditions, impartial prizes, and correspondence with the partners (Anwar \& Louis, 2017). Many models or theories have been carried out regarding job satisfaction. According to Robbins and Judge (2009), job satisfaction describes a positive feeling about a job, resulting from an evaluation of its characteristics. Job satisfaction is conceptualized as a general attitude toward an object, the job (Anwar \& Abdullah, 2021). Job satisfaction as any combination of psychological, physiological and environmental circumstances that cause a person truthfully to say I am satisfied with my job (Anwar \& Abdullah, 2021). A person with a high level of job satisfaction holds positive feelings about his or her job, while an unsatisfied person holds negative feelings. Job satisfaction is a pleasurable positive state resulting from one's job and job experience (Anwar \& Abdullah, 2021). There are, of course, a few largely unimportant variations to the general contact. Anwar \& Shukur, (2015) talked about these distinctions. As a rule, in this way, job satisfaction alludes to a man's valuable powerful reaction to a specific occupation. As indicated by this methodology in spite of the fact that job satisfaction is affected by numerous outside elements, it remains something inward that needs to do with the way how the worker feels. That is job satisfaction shows an arrangement of variables that bring about a sentiment fulfillment. Vroom in his definition on job satisfaction concentrates on the part of the worker in the work environment. Subsequently he characterizes job satisfaction as full of feeling introductions with respect to people toward work parts which they are in a matter of seconds involving (Anwar \& Abd Zebari, 2015). According to Anwar \& Surarchith, (2015) people show pleasurable inspirational states of mind when they are fulfilled by their employment. It is a full of feeling response to a job that outcomes from the individual's correlation of real results with those that are coveted, foreseen or merited. Be that as it may, the aftereffects of the numerous studies 
concerning the relationship between job satisfaction and the sex of the representatives have been conflicting (Anwar, 2017). Job satisfaction speaks to a blend of positive or negative emotions that laborers have towards their work. In the interim, when a specialist utilized in a business organization, carries with it the necessities, yearnings and encounters which determinates desires that he has released. Job satisfaction speaks to the degree to which desires are and coordinate the genuine honors. Job satisfaction is firmly connected to that individual's conduct in the work place (Anwar, 2016). Herzberg et al. (1959) characterized the best known prevalent "hypothesis of job satisfaction". Their two-component hypothesis recommends that representatives have for the most part two sorts of requirements, recorded as hygiene and motivation (Abdulla et al. 2017). Hygiene components are the necessities that might be exceptionally fulfilled by some specific conditions called hygiene variables (disappoints, for example, supervision, interpersonal relations, physical working conditions, compensation, advantages, and so forth. One basic clarification for the distinctive level of work satisfaction at times reported for men and ladies is that ladies have diverse desires with respect to work (Anwar \& Balcioglu, 2016). Job satisfaction is a specialist's feeling of accomplishment and accomplishment at work. It is by and large seen to be straightforwardly connected to profitability and additionally to individual prosperity. Work fulfillment infers doing some work one appreciates, doing it well and being compensated for one's endeavors. Job satisfaction further infers excitement and satisfaction with one's work. Job satisfaction is the key fixing that prompts acknowledgment, salary, advancement, and the accomplishment of different objectives that prompt a sentiment satisfaction (Hameed \& Anwar, 2018). Anwar \& Ghafoor, (2017) meaning of job satisfaction as a disposition that people have about their employments. It results from their impression of their employments and the extent to which there is solid match between the people and the associations. It was uncovered that professions were of focal significance to men however not as vital to women (Anwar \& Climis, 2017). Job satisfaction can be characterized likewise as the degree to which a laborer is content with the prizes, he or she escapes his or her employment, especially as far as inborn inspiration (Anwar \& Qadir, 2017). The term job satisfactions allude to the demeanor and emotions individuals have about their work. Positive and ideal demeanors towards the employment demonstrate job satisfaction. Negative and unfavorable demeanors towards the employment show job dissatisfaction (Anwar \& Louis, 2017). Along these lines chiefs ought to be worried with the level of satisfaction in their organization and a definitive go for the individuals who arrange and control laborers is dissatisfaction (Anwar \& Abdullah, 2021). Job satisfaction is the accumulation of feeling and convictions that individuals have about their present place of employment. Individuals' levels of degrees of occupation fulfillment can go from extreme satisfaction to extreme dissatisfaction. In addition, having dispositions about their jobs in general. Individuals additionally can have states of mind about different parts of their jobs, for example, the sort of work they do, their colleagues, managers or subordinates and their pay (Anwar \& Abdullah, 2021). We consider that job satisfaction speaks to an inclination that shows up as a consequence of the recognition that the job enables the material and mental needs (Saleh et al. 2021).

\section{Affective commitment}

Affective commitment identifies with the number of employees need to stay at their organization. In the event that an employee is affectively committed to their organization, it implies that they want to stay at their organization (Othman \& Abdullah, 2016). They commonly relate to the organizational goals, feel that they fit into the organization and are fulfilled by their work. Employees who are affectively committed feel esteemed, go about as representatives for their organization and are for the most part extraordinary resources for organization. If you have a high level of affective commitment(Abdullah \& Othman, 2016), you enjoy your relationship with the organization and are likely to stay(Abdullah \& Othman, 2021). You stay because you want to stay. An employee of a business who displays affective commitment to their company will often identify strongly with the company and its objectives, and might turn down offers to move to a new company, even if they seem more attractive financially (Anwar \& Abdullah, 2021).

\section{Normative commitment}

Normative commitment refers to the commitment or obligation that the individual feels because of the advantages, for example, preparing, training, and learning opportunities, profession development given by the organization to the person. The sentiment commitment makes the individual more dedicated as the inclination that the organization has contributed on the individual makes him stay in the organization to "reimburse the obligation" the worker stays with the organization in standardizing responsibility since he "ought to" (Anwar \& Shukur, 2015).

\section{Continuous commitment}

Continuous commitment which demonstrates the risk to the person of specific losses that the employee would cause if they somehow managed to leave organization. Here the dedication of the representative to the organization is because of the reason that the choice of quitting from the 
organization is excessive for the worker. He/she sees high cost from losing the enrollment of the organization. This expense incorporates the (monetary cost, for example, annuity and (social cost, for example, (fellowship with the collaborators. There is more commitment to the organization in duration duty since he she "needs to" (Anwar \& Abd Zebari, 2015).

\section{Job satisfaction}

Job satisfaction is crucial problem for all organization regardless of whether out in the open or private organization or working in cutting edge or immature nations. One of the reasons for this level of hobby is that satisfied staff is accounted for as conferred laborers and responsibility is sign for organizational output and useful operations has been characterized in a wide range of ways. Some trust it is basically how content an individual is with his or her employment, at the end of the day, regardless of whether they like the occupation or individual perspectives or aspects of occupations, for example, nature of work or supervision. Others trust it is not all that shortsighted as this definition proposes and rather that multidimensional mental reactions to one's employment are involved. Researchers have additionally noticed that job satisfaction measures shift in the degree to which they quantify sentiments about the job (affective job satisfaction). or comprehensions about the occupation (cognitive job satisfaction) (Anwar \& Surarchith, 2015).

\section{RESEARCH METHODOLOGY}

This research was carried out at the three different private universities. A quantitative method was used to gather relevant information regarding the relationship between organizational commitment and job satisfaction.

\section{Design of the study}

The researcher used a questionnaire in order to collect data about the relationship between organizational commitment and job satisfaction. The questionnaire was composed of two sections. The first section consisted of demographic questions, starting with the respondent's age, gender, level of education, years of experience in respondent's current position, respondent's position. The second section of the questionnaire consisted of questions to measure the organizational commitment and its relationship with job satisfaction in private universities in Kurdistan and particularly in Erbil.

\section{Procedures Used for Generating, Collecting and Evaluating Data}

The researcher gathered data for the study through distributing questionnaires as primary data. The questionnaire is prepared and distributed to the employees at three different private universities. Secondary data is needed for conducting research work, which is done by collecting it from recent academic articles, books and previous studies related to the relationship between organizational commitment and job satisfaction.

\section{Sampling size and target population}

A random sampling method was adopted to collect data, where all the departments and employees in three different private universities will have equal chances of being selected from the sample group. For X private university the researchers distributed 60 questionnaires, but the researchers received 52 questionnaires being completed properly, the researchers distrusted 60 questionnaires at $\mathrm{Y}$ private University but the researchers received 54 questionnaires being completed properly and the researchers distributed 60 questionnaires at $\mathrm{Z}$ private university, but the researchers received 51 questionnaires being completed properly. The sample size is 157 employees participated in this research from three different private universities in Erbil.

\section{Instrument for measuring (scales)}

The questionnaire is structured in the form of multiplechoice questions. The participants were asked to rate how strongly they agree on each item on a five-points Likert order scale. The questionnaire is designed and adapted from the resources. The questionnaire adopted from different sources.

\section{DATA ANALYSIS}

\section{Demographic analysis}

It was found that the number of participant's age that helped us to solve the questioners which was between $(18$ and +60$)$ which they were 157 participants, 45 of them were between (18-29) which makes \%28.7, 63 of them were between (3039) which makes $\% 40.1$ and 30 of them were between (4049) which makes $\% 19.1,12$ of those participants were between (50-51) that makes $\% 7.1$ and 6 of the participants were 60 and above which makes $\% 4.5$. It was found that the number of male and female participant that helped us to solve the questioners which was 157 participants, 117 of those were male which makes about $\% 74.5$ and 40 of them were females which makes about \%25.5. It was found that the participant's level of education that helped us to solve the questioners and they were mostly in the field of business and management and they have degrees such as bachelor, master and $\mathrm{PhD}$ which they were 157 participants, 18 of them were having bachelor degree that makes about \%11.5 and 90 of the participants were having master's degree and that makes \%57.3, 49 of them were having $\mathrm{PhD}$ and that makes \%31.2. It was found that the number of participant's 
year of experience that helped us to solve the questioners which was between $(1$ and +16) which they were 157 participant, 30 of them were between (0-1) which makes $\% 1901,66$ of them were between $(1-5)$ years which makes $\% 42$ and 30 of them were between $(6-10)$ years which makes \%19.1, 24 of those participants were between (11 15) years of experience that makes $\% 15.3$ and 7 of the participants were $16+$ years of experience which makes $\% 4.5$.

Table 1-Demographic analysis

\begin{tabular}{|c|c|c|c|c|}
\hline No & Item & Scales & Frequency & Percent \\
\hline \multirow{5}{*}{1} & \multirow{5}{*}{ Age } & $18-29$ & 45 & 28.7 \\
\hline & & $30-39$ & 63 & 40.1 \\
\hline & & $40-49$ & 30 & 19.1 \\
\hline & & $50-59$ & 12 & 7.6 \\
\hline & & $60+$ & 7 & 4.5 \\
\hline \multirow{2}{*}{2} & \multirow{2}{*}{ Gender } & Male & 117 & 74.5 \\
\hline & & Female & 40 & 25.5 \\
\hline \multirow{3}{*}{3} & \multirow{3}{*}{ Level of education } & bachelor & 18 & 11.5 \\
\hline & & master & 90 & 57.3 \\
\hline & & $\mathrm{PhD}$ & 49 & 31.2 \\
\hline \multirow{5}{*}{4} & \multirow{5}{*}{ Years of experience } & $<1$ year & 30 & 19.1 \\
\hline & & $1-5$ & 66 & 42.0 \\
\hline & & $6-10$ & 30 & 19.1 \\
\hline & & $11-15$ & 24 & 15.3 \\
\hline & & $16+$ & 7 & 4.5 \\
\hline
\end{tabular}

Table 2-Descriptive Statistics

\begin{tabular}{|c|c|c|c|c|c|}
\hline \multicolumn{6}{|c|}{ Descriptive Statistics } \\
\hline Questions & $\mathrm{N}$ & Min & Max & Mean & $\begin{array}{c}\text { Std. } \\
\text { Deviation }\end{array}$ \\
\hline $\begin{array}{l}\text { Q1. I would be happy to spend the rest of my } \\
\text { career with this organization. }\end{array}$ & 157 & 1 & 5 & 2.57 & 1.468 \\
\hline $\begin{array}{l}\text { Q2. I enjoy discussing my organization with } \\
\text { people outside it. }\end{array}$ & 157 & 1 & 5 & 2.99 & .840 \\
\hline $\begin{array}{l}\text { Q3. I really feel as if this organization's } \\
\text { problems are my own. }\end{array}$ & 157 & 1 & 5 & 3.08 & 1.480 \\
\hline $\begin{array}{l}\text { Q4. I do feel like 'part of family' of this } \\
\text { organization. }\end{array}$ & 157 & 1 & 5 & 3.17 & 1.128 \\
\hline $\begin{array}{l}\text { Q5. This organization has a 'sentimental value' } \\
\text { to me. }\end{array}$ & 157 & 1 & 5 & 2.20 & 1.293 \\
\hline $\begin{array}{l}\text { Q6. I do feel a strong sense of belonging to this } \\
\text { organization. }\end{array}$ & 157 & 1 & 5 & 2.51 & 1.426 \\
\hline $\begin{array}{l}\text { Q7. I am afraid of what might happen if I quit } \\
\text { my job without having another one lined up. }\end{array}$ & 157 & 1 & 5 & 3.54 & 1.380 \\
\hline
\end{tabular}




\begin{tabular}{|c|c|c|c|c|c|}
\hline $\begin{array}{l}\text { Q8. It would be very hard for me to leave this } \\
\text { organization right now, even if I wanted to. }\end{array}$ & 157 & 1 & 5 & 2.84 & 1.496 \\
\hline $\begin{array}{l}\text { Q9. My life would be disrupted if I decided I } \\
\text { wanted to leave this organization now. }\end{array}$ & 157 & 1 & 5 & 2.39 & 1.457 \\
\hline $\begin{array}{l}\text { Q10. Right now, staying with this organization } \\
\text { is a matter of necessity as much as desire }\end{array}$ & 157 & 1 & 5 & 3.09 & 1.623 \\
\hline $\begin{array}{l}\text { Q11. I feel that I have a few options to consider } \\
\text { leaving this organization. }\end{array}$ & 157 & 1 & 5 & 3.36 & 1.225 \\
\hline $\begin{array}{l}\text { Q12. One of the few serious consequences of } \\
\text { leaving this organization would be scarcity of } \\
\text { available alternatives. }\end{array}$ & 157 & 1 & 5 & 4.08 & 1.003 \\
\hline $\begin{array}{l}\text { Q13. I think people these days move from } \\
\text { company to company too often. }\end{array}$ & 157 & 1 & 5 & 3.24 & 1.204 \\
\hline $\begin{array}{l}\text { Q14. I do believe that a person must always be } \\
\text { loyal to his/her organization. }\end{array}$ & 157 & 1 & 5 & 4.36 & .928 \\
\hline $\begin{array}{l}\text { Q15. One of the major reasons I continue to } \\
\text { work for this organization is that leaving would } \\
\text { require considerable personal sacrifice-(another } \\
\text { organization may not match the overall benefit I } \\
\text { have here). }\end{array}$ & 157 & 1 & 5 & 2.46 & 1.591 \\
\hline $\begin{array}{l}\text { Q16. Most people in this organization are } \\
\text { satisfied with the job that done now }\end{array}$ & 157 & 1 & 5 & 1.80 & 1.089 \\
\hline $\begin{array}{l}\text { Q17. If I got another offer for a better job } \\
\text { elsewhere I would not feel it was right to leave } \\
\text { the organization. }\end{array}$ & 157 & 1 & 5 & 2.57 & 1.541 \\
\hline $\begin{array}{l}\text { Q18. I was taught to believe in the value of } \\
\text { remaining loyal to one organization. }\end{array}$ & 157 & 1 & 5 & 3.21 & 1.446 \\
\hline
\end{tabular}

According to our statistics results, we have found that the employees are not committed to their organizations and they are unhappy to spent the rest of their life with their organization and this result which was answered negatively according to 2.57 mean of the statistics which was answered by 157 participants. According to our statistics results, we have found that the employees are not committed to their organizations and they are unhappy to talk about their organizations outside of the organization and this result which was answered negatively according to 2.99 mean of the statistics which was answered by 157 participants. According to our statistics results, we have found that the employees are not committed to their organizations and they are unhappy because organizations problem increasing their problem of the organization and this result which was answered negatively according to 3.08 mean of the statistics which was answered by 157 participants. According to our statistics result, we have found that the employees are seeing the organization as their own family not because of the commitment to the organization but because of the friendship of the organization members. According to our statistics results, we have found that the employees are not committed to their organizations and they don't see that the organization has any sentimental value and this result which was answered negatively according to 2.20 mean of the statistics which was answered by 157 participants. According to our statistics results, we have found that the employees are not committed to their organizations and they don't feel sense of belonging to the organization and this result which was answered negatively according to 2.51 mean of the statistics which was answered by 157 participants. According to our statistics results, we found that the employees are continuously committee to the organization because they are afraid of losing their job and this result which was answered positively according to 3.54 mean of the statistics which was answered by 157 participants. According to our statistics results, we have found that the employees are not committed to their organizations and they feel that it would be hard to leave the organization and this result which was answered negatively 
according to 2.84 mean of the statistics which was answered by 157 participants. According to our statistics results, we have found that the employees are not committed to their organizations and they don't feel that their life is going to be disrupted if they leave their organization and this result which was answered negatively according to 2.39 mean of the statistics which was answered by 157 participants. According to our statistics results, we found that the employees are normatively committed to the organization because the they feel necessity as much as desire to stay at the organization and this result which was answered positively according to 3.09 mean of the statistics which was answered by 157 participants. According to our statistics results, we found that the employees are continuously committed to the organization because the they don't have other options to leave the organization and this result which was answered positively according to 3.24 mean of the statistics which was answered by 157 participants. According to our statistics results, we found that the employees are continuously committed to the organization because the consequences of leaving this organization would be scarcity of available alternatives. This result which was answered positively according to 3.09 mean of the statistics which was answered by 157 participants. According to our statistics results, we found that the employees are not satisfied in the organization because of this people move from one organization to another too often This result which was answered positively according to 3.09 mean of the statistics which was answered by 157 participants. According to our statistics results, we found that the employees are affectively committed to the organization because most nearly all of the employees think that they should be loyal to the organization and This result which was answered positively according to 4.36 mean of the statistics which was answered by 157 participants. According to our statistics results, we found that the employees are continuously committed to the organization because One of the major reasons I continue to work for this organization is that leaving would require considerable personal sacrifice-(another organization may not match the overall benefit I have here) and This result which was answered negatively according to 2.46 mean of the statistics which was answered by 157 participants. According to our statistics results, we found that the employees are unhappy and not satisfied to the organization because most of the employees are not satisfied and this result which was answered negatively according to 2.46 mean of the statistics which was answered by 157 participants. According to our statistics results, we found that the employees are continuously committed to the organization because they think that it's not ethical to leave the organization and this result which was answered negatively according to 2.57 mean of the statistics which was answered by 157 participants. According to our statistics results, we found that the employees are affectively committed to the organization because they think that they should be loyal to the organization and this result which was answered positively according to 3.21 mean of the statistics which was answered by 157 participants

\section{CONCLUSION}

This research investigated the relationship between employees' commitment and job satisfaction in private university's in Erbil. In KRG job satisfaction of the workers relies more upon the continuance commitment of employees. It demonstrates a positive indication of the employees revealing the attachment and commitment of employees to the organization. According to multiple regression analysis employees are committed to their job because of remuneration and lack of alternatives. Also, the results revealed that all three independent factors are correlated with job satisfaction. The result can be used as a guiding method for the university's management to increase their employees' commitment. Job satisfaction has a positive relation with employee commitment if employees are satisfied, they are organizationally committed we found that job satisfaction has a positive impact on employee commitment, it is really important for job satisfaction that employees are committed, the purpose of this investigation was to determine the levels of employees of public sector satisfaction with job dimensions and perceived organizational commitment in public sector in Shkoder, Albania. In addition, the study aimed at exploring to what extent these employees are committed to their job and satisfied with different dimensions to their job. A surveybased descriptive research design was used. The study was carried on public administrative sector, The current findings of a low level of satisfaction with promotion, and a strong positive correlation between job satisfaction and organizational commitment, suggest that improving this facet could lead to an improvement in organizational commitment in this sample.

\section{REFERENCES}

[1] Teo, S. T., Bentley, T., \& Nguyen, D. (2020). Psychosocial work environment, work engagement, and employee commitment: A moderated, mediation model. International Journal of Hospitality Management, 88, 102415.

[2] Kowalczyk, R., \& Kucharska, W. (2020). Corporate social responsibility practices incomes and outcomes: Stakeholders' pressure, culture, employee commitment, corporate reputation, and brand performance. A PolishGerman cross-country study. Corporate Social 
Responsibility and Environmental Management, 27(2), 595615.

[3] Kucharska, W. (2020). Employee commitment matters for CSR practice, reputation and corporate brand performance-European model. Sustainability, 12(3), 940.

[4] Abdullah, N. N., \& Othman, M. B. (2019). Effects of Intellectual Capital on the Performance of Malaysian Food and Beverage Small and Medium-Sized Enterprises. International Journal of Civil Engineering and Technology (IJCIET), 10(2), 135-143.

[5] Anwar, G., \& Abdullah, N. N. (2021). Inspiring future entrepreneurs: The effect of experiential learning on the entrepreneurial intention at higher education. International Journal of English Literature and Social Sciences, 6.

[6] Gardi, B., Hamawandy, N. M., Vian Sulaiman Hama Saeed, R. M. A., Sulaiman, A. A., Mahmood, S. A., \& Al-Kake, F. A. (2020). The Effect of Capital Competence on the Profitability of Development and Investment Banks in Turkey. Solid State Technology, 63(6), 12571-12583.

[7] Prabhu, M., Nambirajan, T., \& Abdullah, N. N. (2020). Operating competitive priorities of manufacturing firms: An analytical study. Journal of Industrial Engineering and Management, 13(1), 38-55.

[8] Anwar, G., \& Shukur, I. (2015). The Impact of Training and Development on Job Satisfaction: A Case Study of Private Banks in Erbil. International Journal of Social Sciences \& Educational Studies, 2(1), 65.

[9] Sultan, K., Ahmed, R. R., Jafar, R., Murtaza, M. M., \& Gardi, B. (2020). Corporate Financial Policy And Its Impact On Sustainable Capital Structure: Empirical Evidence From Textile Firms Of Pakistan.

[10] Abdullah, N. N., \& Othman, M. (2015). Disaster Management: Empirical Study of 2009 Jeddah Flood. Abdullah, NN \& Othman, M.(2015). Disaster Management: Empirical Study of, 1083-1087.

[11] Gardi, B. (2021). Investigating the effects of Financial Accounting Reports on Managerial Decision Making in Small and Medium-sized Enterprises. Turkish Journal of Computer and Mathematics Education (TURCOMAT), 12(10), 2134-2142.

[12] Anwar, G., \& Shukur, I. (2015). Job satisfaction and employee turnover intention: A case study of private hospital in Erbil. International Journal of Social Sciences \& Educational Studies, 2(1), 73.

[13] Ismael, N. B., Sorguli, S., Aziz, H. M., Sabir, B. Y., Hamza, P. A., Gardi, B., \& Al-Kake, F. R. A. (2021). The Impact of COVID-19 on Small and Medium-Sized Enterprises in Iraq. Annals of the Romanian Society for Cell Biology, 24962505.

[14] Anwar, G., \& Shukur, I. (2015). the impact of recruitment and selection on job satisfaction: Evidence from private school in Erbil. International Journal of Social Sciences \& Educational Studies, 1(3), 4-13.

[15] Gardi, B. (2021). The effects of computerized accounting system on auditing process: a case study from northern Iraq. Available at SSRN 3838327.

[16] Anwar, G., \& Abd Zebari, B. (2015). The Relationship between Employee Engagement and Corporate Social
Responsibility: A Case Study of Car Dealership in Erbil, Kurdistan. International Journal of Social Sciences \& Educational Studies, 2(2), 45.

[17] Anwar, G., \& Surarchith, N. K. (2015). Factors Affecting Shoppers' Behavior in Erbil, Kurdistan-Iraq. International Journal of Social Sciences \& Educational Studies, 1(4), 10.

[18] Othman, B. J., Al-Kake, F., Diah, M. L. M., Othman, B., \& Hasan, N. M. (2019). This study examines the antecedents and the effects of knowledge management and information technology in the manufacturing industry. International Journal of Psychosocial Rehabilitation, 23(02).

[19] Khan, S. \& Abdullah, N. N. (2019). The effect of ATM service quality on customer's satisfaction and loyalty: an empirical analysis. RJOAS, 5(89): DOI 10.18551/rjoas.2019-05.28

[20] Anwar, G., \& Shukur, I. (2015). The Impact of Service Quality Dimensions on Students' Satisfaction. International Journal of Social Sciences \& Educational Studies, 76.

[21] Othman, B. J., Al-Kake, F., Diah, M. L. M., Othman, B., Hussein, S., \& Hasan, N. M. (2019). Impact of the foreign direct investment on the economy of the United Kingdom. International Journal of Psychosocial Rehabilitation, 23(02).

[22] Anwar, K. (2017). Analyzing the conceptual model of service quality and its relationship with guests'satisfaction: A STUDY OF HOTELS IN ERBIL. The International Journal of Accounting and Business Society, 25(2), 1-16.

[23] Anwar, K. (2016). Comparison between cost leadership and differentiation strategy in agricultural businesses. Custos $\mathrm{E}$ Agronegocio on Line, 12(2), 212-231.

[24] Abdullah, M. S., Toycan, M., \& Anwar, K. (2017). The cost readiness of implementing e-learning. CUSTOS E AGRONEGOCIO ON LINE, 13(2), 156-175.

[25] Anwar, K., \& Balcioglu, H. (2016). The relationship between transformational leadership characteristics and effectiveness: A case study of construction companies in Erbil. International Journal of Science Technology and Management, 5(2), 250-256.

[26] Abdullah, N. N., \& Abdul Rahman, M. (2015). The Degree of Openness in Turkey's Public Expenditure. International Journal of Administration and Governance, 12(1), 8-12.

[27] Anwar, K. (2017). The Role of Effective Leadership in Crisis Management: Study of Private Companies in Kurdistan. Qalaai Zanist Scientific Journal, 2(4), 326-338.

[28] Hameed, A. A., \& Anwar, K. (2018). Analyzing the Relationship between Intellectual Capital and Organizational Performance: A Study of Selected Private Banks in Kurdistan. International Journal of Social Sciences \& Educational Studies, 4(4), 39.

[29] Damit, D. H. D. A., Harun, A., Martin, D., Othman, B., \& Ahmad, H. (2019). What makes a non-Muslim purchase halal food in a Muslim country? An application of theory of planned behaviour. Management Science Letters, 9(12), 2029-2038.

[30] Anwar, K., \& Ghafoor, C. (2017). Knowledge management and organizational performance: A study of private universities in Kurdistan. International Journal of Social Sciences \& Educational Studies, 4(2), 53. 
[31] Prabhu, M., Thangasamy, N., \& Nawzad Abdullah, N. (2020). Analytical review on competitive priorities for operations under manufacturing firms. Journal of Industrial Engineering and Management, 13(1), 38-55.

[32] Anwar, K., \& Climis, R. (2017). Analyzing the relationship between types of advertisement and customer choice: a study of retailer stores in Erbil. The International Journal of Accounting and Business Society, 25(2), 43-52.

[33] Anwar, K. (2017). Factors Affecting Stock Exchange Investment In Kurdistan. The International Journal of Accounting and Business Society, 25(1), 32-37.

[34] Prabhu, M., Abdullah, N. N. \& Mohan, M. G. (2019). An Empirical Study on the Satisfaction Level of National and International Tourists towards Natural Attractions in Kurdistan. African Journal of Hospitality, Tourism and Leisure, 8 (2). 1-8

[35] Anwar, K., \& Qadir, G. H. A Study of the Relationship between Work Engagement and Job Satisfaction in Private Companies in Kurdistan. International Journal of Advanced Engineering, Management and Science, 3(12), 239944.

[36] Abdullah, NN \& Rahman, MFA (2015). The Use of Deliberative Democracy in Public Policy Making Process. Public Policy and Administration Research, 5(3), 221-229.

[37] Anwar, K. (2017). Leading Construction Project Teams: The Effectiveness of Transformational Leadership in Dynamic Work Environments in Kurdistan. International Journal of Advanced Engineering, Management and Science, 3(10), 239925.

[38] Abdullah, N. N. (2019). Probing the Level of Satisfaction towards the Motivation Factors of Tourism in Kurdistan Region. Scholars Journal of Economics, Business and Management, 5 (6). 439-443.

[39] Anwar, K., \& Louis, R. (2017). Factors Affecting Students' Anxiety in Language Learning: A Study of Private Universities in Erbil, Kurdistan. International Journal of Social Sciences \& Educational Studies, 4(3), 160.

[40] Ali, B. J., \& Anwar, G. (2021). The Effect of Marketing Culture Aspects of Healthcare Care on Marketing Creativity. Ali, BJ, \& Anwar, G.(2021). The Effect of Marketing Culture Aspects of Healthcare Care on Marketing Creativity. International Journal of English Literature and Social Sciences, 6(2), 171-182.

[41] Ali, B. J., \& Anwar, G. (2021). An Empirical Study of Employees' Motivation and its Influence Job Satisfaction. Ali, BJ, \& Anwar, G.(2021). An Empirical Study of Employees' Motivation and its Influence Job Satisfaction. International Journal of Engineering, Business and Management, 5(2), 21-30.

[42] Khan, S. I., \& Abdullah, N. N. (2019). The impact of staff training and development on teachers' productivity. Economics, Management and Sustainability, 4(1), 37-45.

[43] Ali, B. J., \& Anwar, G. (2021). The balanced scorecard's evolution as a strategic mechanism at banking sectors. Ali, BJ, \& Anwar, G.(2021). The Balanced Scorecard'S Evolution as a Strategic Mechanism at Banking Sectors. International Journal of English Literature and Social Sciences, 6(1), 471-478.
[44] Anwar, G., \& Abdullah, N. N. (2021). The impact of Human resource management practice on Organizational performance. International journal of Engineering, Business and Management (IJEBM), 5.

[45] Abdullah, N. N., \& Anwar, G. (2021). An Empirical Analysis of Natural Gas as an Alternative Fuel for Internal Transportation. International Journal of English Literature and Social Sciences, 6(1).

[46] Ali, B. J., \& Anwar, G. (2021). Factors Influencing the Citizens' Acceptance of Electronic Government. International journal of Engineering, Business and Management (IJEBM), 5.

[47] Anwar, G., \& Abdullah, N. N. (2021). Inspiring future entrepreneurs: The effect of experiential learning on the entrepreneurial intention at higher education. International Journal of English Literature and Social Sciences, 6.

[48] Prabhu, M., Abdullah, N.N., Ahmed, R.R. (2020). Segmenting the manufacturing industries and measuring the performance: using interval-valued triangular fuzzy TOPSIS method. Complex Intell. Syst.. https://doi.org/10.1007/s40747-020-00157-0

[49] Ali, B. J., \& Anwar, G. (2021). A study of knowledge management alignment with production management: A study of carpet manufacture in Kurdistan region of Iraq. Ali, BJ, \& Anwar, G.(2021). A Study of Knowledge Management Alignment with Production Management: a Study of Carpet Manufacture in Kurdistan Region of Iraq. International Journal of English Literature and Social Sciences, 6(2), 346-360.

[50] Ganeshkumar, C., Prabhu, M., \& Abdullah, N. N. (2019). Business Analytics and Supply Chain Performance: Partial Least Squares-Structural Equation Modeling (PLS-SEM) Approach. International Journal of Management and Business Research

[51] Ali, B. J., \& Anwar, G. (2021). Business strategy: The influence of Strategic Competitiveness on competitive advantage. International Journal of Electrical, Electronics and Computers, 6(2).

[52] Abdullah, N. N. \& Afshar, P. A. (2019). Investigating research and development costs on the profitability of Iranian industries. Journal of Organizational Behavior Research. Volume 4 (S2). 1-14

[53] Ali, B. J., \& Anwar, G. (2021). Marketing Strategy: Pricing strategies and its influence on consumer purchasing decision. Ali, BJ, \& Anwar, G.(2021). Marketing Strategy: Pricing strategies and its influence on consumer purchasing decision. International journal of Rural Development, Environment and Health Research, 5(2), 26-39.

[54] Abdullah, NN, \& Rahman, MFA (2015). Access to Government Information in Public Policy Making Process: A Case Study of Kurdistan. International Information Institute (Tokyo). Information, 18(8), 3447

[55] Ali, B. J., Saleh, P. F., Akoi, S., Abdulrahman, A. A., Muhamed, A. S., Noori, H. N., \& Anwar, G. (2021, May). Impact of Service Quality on the Customer Satisfaction: Case study at Online Meeting Platforms. In Ali, BJ, Saleh, Akoi, S., Abdulrahman, AA, Muhamed, AS, Noori, HN, Anwar, G.(2021). Impact of Service Quality on the 
Customer Satisfaction: Case study at Online Meeting Platforms. International journal of Engineering, Business and Management (Vol. 5, No. 2, pp. 65-77)

[56] Abdullah, N. N. (2018). Probing the Level of Satisfaction towards the Motivation Factors of Tourism in Kurdistan Region. 5(6), 439-443. DOI: 10.21276/sjebm.2018.5.6.3

[57] Ali, B. J., \& Anwar, G. (2021). Strategic leadership effectiveness and its influence on organizational effectiveness. International Journal of Electrical, Electronics and Computers, 6(2).

[58] Saleh, P. F., Ali, B. J., Akoi, S., Najmalddin, B., Ali, R. S., \& Anwar, G. (2021). Factors affecting the Success of Female Entrepreneurs in Kurdistan. International journal of Engineering, Business and Management (IJEBM), 5.

[59] Othman, M., \& Abdullah, N. N. (2016). The Conceptual Assessment of Malaysian Entrepreneurship Environment and EO Economic Contribution. Journal of Resources Development and Management, 20, 15-20.

[60] Ali, B. J., \& Anwar, G. (2021). Intellectual capital: A modern model to measure the value creation in a business. Ali, BJ, \& Anwar, G.(2021). Intellectual capital: A modern model to measure the value creation in a business. International journal of Engineering, Business and Management, 5(2), 31-43.

[61] Abdullah, N. N., \& Othman, M. (2016). The Contribution of Human Capital Investment in the Growth of East Asian Economy-A Literature Review. Journal of Economic and Business Research, 22(1), 190-203.

[62] Ali, B. J., \& Anwar, G. (2021). Organization citizenship behaviour as a determining Factor in Business outcome. Ali, BJ, \& Anwar, G.(2021). Organization citizenship behaviour as a determining Factor in Business outcome. International journal of Rural Development, Environment and Health Research, 5(2), 17-25.

[63] Abdullah, N. N., \& Othman, M. B. (2021). Investigating the Limitations of Integrated Tasks on Youth Entrepreneurship in Kurdistan Region. Путеводитель предпринимателя, 14(2), 179-190.

[64] Abdullah, N. N., \& Abdul Rahman, M. (2015). Chinese Economic Activities and Interests in Developing Countries. Australian Journal of Basic and Applied Sciences, 9(25), 7986.

[65] Ali, B. J., \& Anwar, G. (2021). The mediation role of change management in employee development. Ali, BJ, \& Anwar, G.(2021). The Mediation Role of Change Management in Employee Development. International Journal of English Literature and Social Sciences, 6(2), 361-374.

[66] Top, C., \& Ali, B. J. (2021). Customer satisfaction in online meeting platforms: Impact of efficiency, fulfillment, system availability, and privacy. Amazonia Investiga, 10(38), 7081. https://doi.org/10.34069/AI/2021.38.02.7

[67] Demir, A., Maroof, L., Sabbah Khan, N.U. and Ali, B.J. (2020), "The role of E-service quality in shaping online meeting platforms: a case study from higher education sector", Journal of Applied Research in Higher Education. https://doi.org/10.1108/JARHE-08-2020-0253

[68] Ali, B, J. (2021). Impact of consumer animosity, boycott participation, boycott motivation, and product judgment on purchase readiness or aversion of Kurdish consumers in Iraq. Journal of Consumers Affaires; 1-20. https://doi.org/10.1111/joca.12350

[69] Ali, B, J. (2020). Impact of COVID-19 on consumer buying behavior toward online shopping in Iraq. Economic studies journal. 18(42): 267-280. Retrieved from https://www.asjp.cerist.dz/en/article/134070

[70] Ali, B.J. (2021) Assessing (The impact) of advertisement on customer decision making: Evidence from an educational institution. Afak for sciences journal, 6(1): 425-439. Retrieved from https://www.asjp.cerist.dz/en/article/141056

[71] Ali, B.J. (2021) Consumer attitudes towards healthy and organic food in the Kurdistan region of Iraq. Management Science Letters. 11: 1-8. DOI: 10.5267/j.ms1.2021.2.015

[72] Andavar, V., Ali, B.J., and Ali, S.A. (2020) Rainwater for Water Scarcity Management: An Experience of Woldia University (Ethiopia). Journal of Business, Economics and Environmental Studies, 10-(4): 29-34. DOI: 10.13106/jbees.2020.vol10.no4.29

[73] Faraj, K. M., Faeq, D. K., Abdulla, D. F., Ali, B. J., \& Sadq, Z. M. (2021). Total Quality Management And Hotel Employee Creative Performance: The Mediation Role Of Job Embeddedment. Journal of Contemporary Issues in Business and Government Vol, 27(1).

[74] Ali, B. J. (2016). Iraq Stock Market and its Role in the Economy. Retrieved from https://www.amazon.com/IraqStock-Market-Role-Economy/dp/3659634271

[75] Ali, B. J. (2014). Brand Building in the Consumer Electronics Industry in Iraq. Retrieved from https://www.amazon.com/Brand-Building-ConsumerElectronics-Industry/dp/6200248699

[76] Ali, B. J., \& Anwar, G. (2021). Capital Structure and Firm Profitability in Developing Countries. GOYA, 68(374), 163-174. Retrieved from https://goyajournal.org/index.php/goya/article/view/35

[77] Ali, B. J., \& Anwar, G. (2021). Factors Influencing the Citizens' Acceptance of Electronic Government. International Journal of Engineering, Business and Management, 5(1), 48-60. https://doi.org/10.22161/ijebm.5.1.5

[78] Ali, B. J., \& Anwar, G. (2021). The Effect of Marketing Culture Aspects of Healthcare Care on Marketing Creativity. International Journal of English Literature and Social Sciences, $\quad 6(2), \quad 171-182$. https://doi.org/10.22161/ijels.62.25

[79] Ali, B. J., \& Anwar, G. (2021). An Empirical Study of Employees' Motivation and its Influence Job Satisfaction. International Journal of Engineering, Business and Management, 5(2), 21-30. https://doi.org/10.22161/ijebm.5.2.3

[80] Ali, B. J., \& Anwar, G. (2021). The balanced scorecard's evolution as a strategic mechanism at banking sectors. International Journal of English Literature and Social Sciences, $\quad 6(1), \quad 471-478$. https://doi.org/10.22161/ijels.61.63

[81] Ali, B. J., \& Anwar, G. (2021). Self-Leadership Skills as Intangible Resources for Sustainable Competitive Advantage. Gongcheng Kexue Yu Jishu/Advanced 
Engineering Science, 46(1), 88-104. Retrieved from https://gongcheng-

journal.com/index.php/AES/article/view/10

[82] Ali, B. J., \& Anwar, G. (2021). Health sector reform: A Change Management Perspective on Health sector Reform. Gongcheng Kexue $\mathrm{Yu}$ Jishu/Advanced Engineering Science, 46(2), 29-38. Retrieved from https://gongchengjournal.com/index.php/AES/article/view/13

[83] Ali, B. J., \& Anwar, G. (2021). Organizational Learning as A Determining Factor in Firm Performance. GOYA, 68(374), 193-202. Retrieved from https://goyajournal.org/index.php/goya/article/view/40 